\title{
Are epigenetic mechanisms involved in radiation-induced bystander effects?
}

\section{Carmel Mothersill * and Colin Seymour}

Department of Medical Physics and Applied Radiation Sciences, McMaster University, Hamilton, ON, Canada

\section{Edited by:}

Igor Kovalchuk, University of

Lethbridge, Canada

\section{Reviewed by:}

Igor Kovalchuk, University of

Lethbridge, Canada

Feng Zhou, Indiana University School

Medicine, USA

\section{*Correspondence:}

Carmel Mothersill, Department of

Medical Physics and Applied

Radiation Sciences, McMaster

University, Hamilton, ON, Canada L8S

$4 K 1$.

e-mail:mothers@mcmaster.ca
The "non-targeted effects" of ionizing radiation including bystander effects and genomic instability are unique in that no classic mutagenic event occurs in the cell showing the effect. In the case of bystander effects, cells which were not in the field affected by the radiation show high levels of mutations, chromosome aberrations, and membrane signaling changes leading to what is termed "horizontal transmission" of mutations and information which may be damaging while in the case of genomic instability, generations of cells derived from an irradiated progenitor appear normal but then lethal and non-lethal mutations appear in distant progeny. This is known as "vertical transmission." In both situations high yields of non-clonal mutations leading to distant occurrence of mutation events both in space and time. This precludes a mutator phenotype or other conventional explanation and appears to indicate a generalized form of stress-induced mutagenesis which is well documented in bacteria. This review will discuss the phenomenology of what we term "non-targeted effects," and will consider to what extent they challenge conventional ideas in genetics and epigenetics.

Keywords: radiation, non-targeted effects, bystander effects, genomic instability, evolution

\section{INTRODUCTION}

As early as 1915, a mere 20 years after Roentgen discovered x-rays, a report was published (Murphy and Norton, 1915) suggesting that ionizing radiation to one part of the body could result in effects in a distant part. This in a nutshell is "the bystander effect." Further discoveries reviewed by the authors (Mothersill and Seymour, 2001, 2012) were published over the years but largely ignored as the field of radiobiology became dominated by target theory and the DNA paradigm. This assumed that DNA was the target for radiation damage in cells and that the damage was the direct result of energy deposition in the cells. The energy deposited, and hence the DNA damage, was directly proportional to dose, leading to complicated explanations for why the experimental evidence demonstrated a curved or linear quadratic response. Repair theory stated that departures from this linear dose-response relationship were due to DNA repair of single or double strand breaks (Hall and Giaccia, 2006).

"The Structure of Scientific Revolutions" by Kuhn (1970) describes in great detail the course of scientific change and the history of low dose radiation biology over the last 25 years fits the theory well. All the classic stages of paradigm shift are there from disbelief, to grudging acceptance, to the claim that of course the "discoveries" were obvious and in the literature since time began.

Over a 10-year period from 1986 to 1996, the dominant idea that all radiation damage resulted in hit cells from energy deposition in those cells' DNA was finally challenged by four key lines of evidence (Figure 1). First in 1986 our group published a paper saying that de novo appearance of lethal mutations could occur in cells which had "recovered" from irradiation and successfully divided for several generations (Seymour et al., 1986). Second, delayed appearance of de novo chromosome aberrations was demonstrated in bone marrow stem cell lineages derived from irradiated stem cells (Kadhim et al., 1992). These non-clonal aberrations could not have been present at the time of irradiation. Third, a very low dose exposure to alpha radiation resulted in more cells showing chromosome damage than could have been hit by the ionizing particles (Nagasawa and Little, 1992) and forth, medium from irradiated cells was found to cause similar levels of clonogenic cell death and genomic instability as direct irradiation (Mothersill and Seymour, 1997; Seymour and Mothersill, 1997). Taken together, these papers started the scientific revolution establishing a new paradigm in low dose radiobiology which now is accepted by most radiation biologists but still not understood. The first two papers revealed that genetic change could occur in distant descendants of irradiated progenitor cells after multiple normal successful divisions (genomic instability) while the latter three papers established that genetic change could be induced in cells which were not affected by the mutagen (ionizing radiation) but were in receipt of signals from the irradiated cells (bystander effect). This review will highlight some of the controversies and discuss implications for mainstream biology.

\section{CHALLENGES TO CONVENTIONAL GENETICS POSED BY NON-TARGETED EFFECTS} HOW CAN YOU HAVE A MUTATION WITHOUT A MUTAGEN?

Perhaps the biggest challenge posed by the discoveries was that cells not targeted by a mutagen could demonstrate heritable genetic change. Ionizing external radiation is a "clean" mutagen in that it does not leave any residue so long term effects cannot be attributed to a persistent chemical legacy. Initial theories to explain genomic instability within the existing framework centered around ideas that a mutator phenotype had been activated (Loeb, 2011) but the 


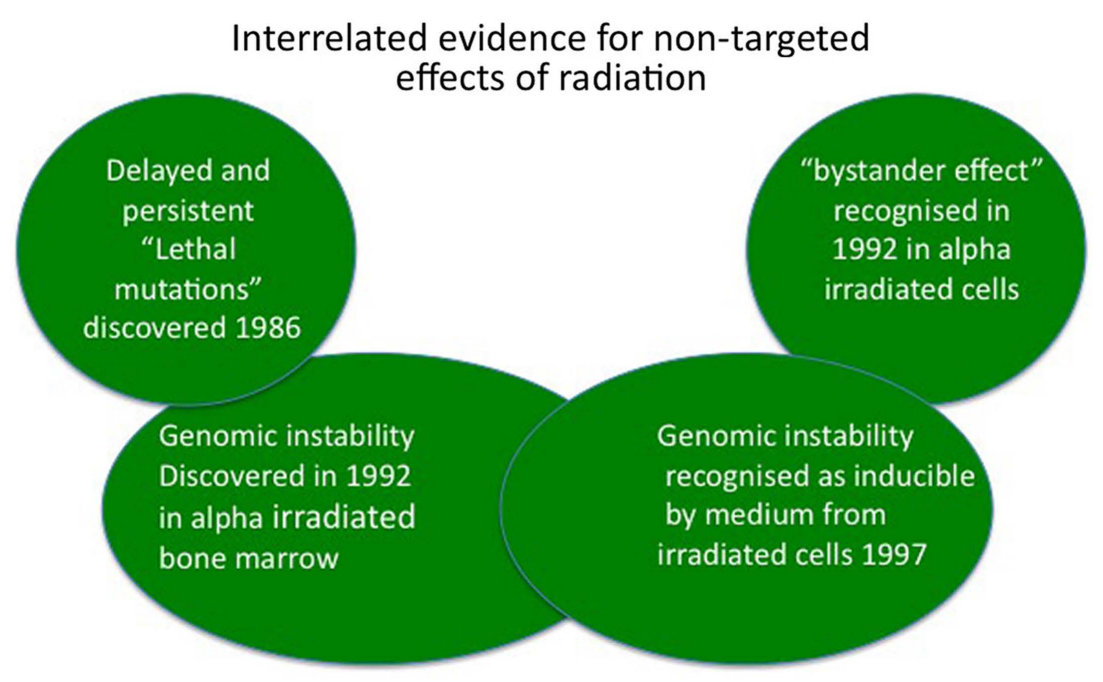

FIGURE 1 | Key initial evidence for non-targeted effects and the interaction between these effects.

very high yields of non-clonal genetic damage inducible even by culture medium from irradiated cells made this unlikely as did the persistent nature of the effect which was neither selected out nor ultimately dominant (Seymour and Mothersill, 1988, 1997; Mendonca et al., 1989). It has been suggested that an external epigenetic driver is involved such as oxy-radicals (Hamada et al., 2011), methylation changes (Kaup et al., 2006; Tamminga and Kovalchuk, 2011), or miRNA mediated signaling (Ilnytskyy et al., 2009; Kovalchuk et al., 2010) but because a single exposure to radiation can turn on the process indefinitely both in vitro and in vivo (O'Reilly et al., 1994; Mothersill et al., 2000, 2010) this hypothesis requires the driver to be permanently activated both in time and in space following a single exposure to ultra-low doses of radiation. An important conceptual point here is that signal generation and response to the signal are separate processes and may not both occur in a single system (Vines et al., 2008). Signal generation appears to be a consequence of electrochemical processes much like those occurring in the nervous system. Depolarization of cell membranes, ion-fluxes, and sensitive responses to neurotransmitters and their inhibitors, characterize signal generation (Poon et al., 2007). The cellular response has been demonstrated to be an inflammatory-like response, involving cytokines, TGF beta, p53, and other proteins involved in the apoptotic or checkpoint control pathways (Hei et al., 2008). The response of the cell or organism is genetically determined with cancer prone organisms and cells having a growth response to the signal while cancer resistant systems have an apoptotic response (Mothersill et al., 2005). It is not known if the initial bystander signal generation is genetically controlled. Efforts to isolate the factor involved in transmission of information from irradiated to bystander cells has been singularly unsuccessful suggesting it is small, transient, or perhaps not chemical. Very recent data from our laboratory (Mothersill et al., in press) suggests a weak electromagnetic or pressure signal might play a role. This idea is highly attractive given the nature of ionizing radiation and the importance of ion-gated signaling in biology but is difficult to prove.

\section{IS LAMARCKIAN GENETICS INVOLVED?}

A second major challenge was posed by the discovery that these effects could be demonstrated not only in cells but also at the level of the tissue, organism, and even population (Figure 2). The tissue and organ level effects were known for some time as episcopal effects (Sgouros et al., 2007) but were ignored as an unimportant curiosity of radiotherapy. Transmission between organisms was first demonstrated by Surinov et al. (2001) in mice and has now been demonstrated in rats, several species of fish and in tadpoles, and is reviewed by the authors (Mothersill and Seymour, 2012). This has practical implications for radiation protection of ecosystems because it implies that protection of the individual might not suffice. It also has fascinating biological implications supporting Lamarckian ideas that cumulative inheritance of modified characteristics could be induced through an environmentally directed mutational shift obviating the randomness characteristic of Darwinian ideas of mutation. In the fields of stress-induced bacterial mutagenesis and plant breeding genetics there is acceptance that exposure to environmental stress can lead to persistent high rates of mutation which are adaptive $a b$ initio rather than selected for. In fact inducible adaptive responses or hormetic responses are characteristic of low dose radiation exposure (Calabrese et al., 2011) and appear to be transmissible through bystander-like signaling processes even between individual animals and plants (Morgan, 2011; Mothersill and Seymour, 2012). This implies that "fitness" can spread through a population before the majority of individuals have experienced the stressor.

\section{ARE THERE IMPLICATIONS FOR ESTABLISHED VIEWS OF CANCER INITIATION?}

A further challenge presented by bystander effects in particular but also by genomic instability was that conventional theories of radiation carcinogenesis were based on the idea of initiation by an ionizing track of a mutation in a cell which ultimately gave rise to a cancer. This clonal origin of radiogenic cancer was used to 


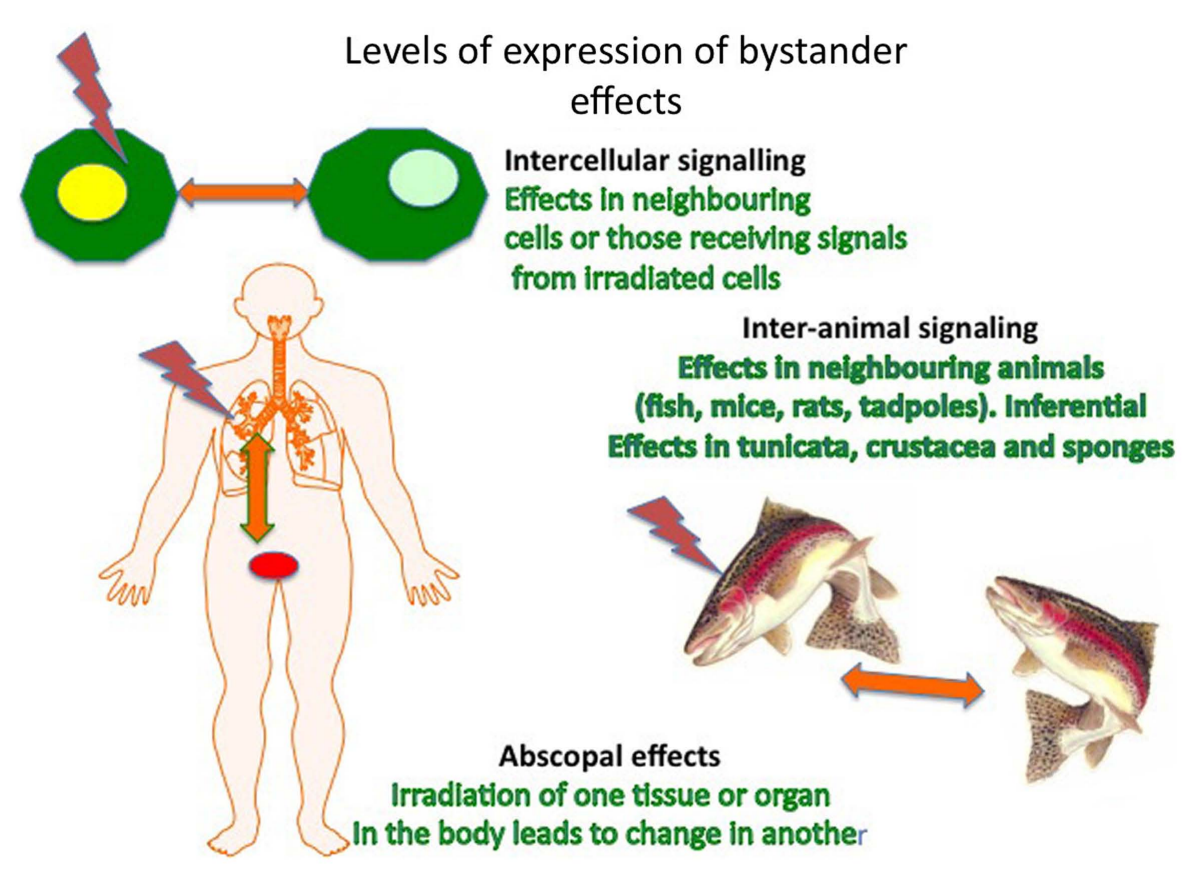

FIGURE 2 | Levels of expression of non-targeted effects in cells, organisms, and populations/ecosystems.

calculate risk of cancer induction by relating risk to number of double strand breaks induced by the dose received. Such thinking is still the basis of radiation epidemiology and is the fundamental assumption of the linear non-threshold (LNT) hypothesis which is the basis of radiation protection. Horizontal and vertical transmission of damage undermine the direct association of a DNA "hit" with development of a cancer and support instead the idea that radiation induces a field change which allows unstable cells to proliferate. Interestingly, a major factor underlying the shift away from LNT is the recent concern to establish a new radiation protection system for non-human species (Bréchignac et al., 2011). Here of course, concern is to protect populations not individuals and cancer is not an issue. The conceptual framework needed to develop new endpoints and biomarkers indicating population level damage at the macro level in biota may also provide insights into possible dose-response relationships and markers for risk from non-targeted effects at the micro level in both cells and tissues.

\section{DO NON-TARGETED EFFECTS CHALLENGE THE VIEW THAT EVOLUTION INVOLVES CONTINUAL IMPROVEMENT?}

Current thinking in radiobiology and radiation protection is divided as to whether non-targeted effects are "good" or "bad." On the one hand, genetic damage such as chromosome aberrations and micronucleus formation can be seen and quantified. Stress effects and induction of DNA repair occur which must indicate damage. However on the other hand protective affects such as induction of adaptive responses and hormesis also occur - so do these effects mean radiation is more or less dangerous than previously thought? There is no clear answer to this question which continually pitches pro- and anti-nuclear activists against each other but it is important to make a number of points and to list endpoints which seem common to both targeted and non-targeted effects (summarized in the Box 1 below).

An important conclusion is that much depends on the level of organization at which "goodness" or "badness" is being assessed. To quote Lamarck " Since each part must necessarily change and cease to exist to make way for the formation of another, each part has an interest which is contrary to that of the whole; and if it reasons, it finds that the whole is badly made. In reality, however, this whole is perfect, and completely fulfills the purpose for which it is destined" (Lamarck, 1963). Implicit in this quotation is the idea that "good" or "bad" can only be answered in terms of the "whole" and that at other levels change equals improvement. Is this true? Many hypothesize (including these authors earlier in this review) that non-targeted effects are drivers of evolutionary change allowing adaptation to environmental change to occur quickly and efficiently. "Mistakes" would lead to the death of the "whole." Darwinian arguments would suggest that bystander factors provide greater rates of random mutation, and hence provide material for natural selection to occur.

The idea of a driver may suggest cause, reason, direction, and improvement, which are central ideas in human philosophy. However it is neither necessary nor possible to comment effectively on this. Just as ionizing radiation tracks in cells are random, their consequences may also be random? If this is true it introduces an uncertainty into radiation biology, which means that radiation is unlike chemical carcinogens and mutagens, which have definable chemical pathways of action and where cause and effect can be plausibly linked. With radiation, electrical perturbation 
Box 1 | Comparison of endpoints of damage or change in directly irradiated cells, bystander cells, and progeny of directly irradiated cells.

The data in the table summarize 25 years of research by numerous authors are comprehensively reviewed in Morgan (2003a,b), Lorimore et al. (2003), Hei et al. (2008), Mothersill and Seymour (2012), and many other reviews.

\begin{tabular}{|c|c|c|c|}
\hline Endpoint & Directly irradiated cells & $\begin{array}{l}\text { Radiation-induced } \\
\text { bystander cells }\end{array}$ & $\begin{array}{l}\text { Progeny of directly } \\
\text { irradiated or bystander cells }\end{array}$ \\
\hline Death & Reproductive death, apoptosis & Apoptosis and other forms of cell death & Delayed reproductive death, apoptosis \\
\hline Protein induction & $\begin{array}{l}\text { Induction of repair and } \\
\text { checkpoint proteins }\end{array}$ & Induction of early response proteins & $\begin{array}{l}\text { Persistent over-expression of stress } \\
\text { proteins in progeny }\end{array}$ \\
\hline Reactive oxygen species & Generation of free radicals & Oxidative stress & Persistent oxidative stress \\
\hline Growth stimulation & Adaptive response & Proliferation and adaptive response & Adaptive response \\
\hline $\begin{array}{l}\text { Non-clonal persistent } \\
\text { mutations }\end{array}$ & Chromosomal aberrations & Genomic instability, lethal mutations & $\begin{array}{l}\text { Genomic instability in progeny and } \\
\text { lethal mutations }\end{array}$ \\
\hline Micronucleus (MN) assay & Increased MN & Cytogenetic effects and increased MN & Cytogenetic effects and increased MN \\
\hline Carcinogenesis & Transformed foci & Transformed foci & Transformation and cancer in vivo \\
\hline Mitochondrial function & Aberrant & Aberrant & Aberrant \\
\hline P53 function & Critical & Critical to response outcome & Critical to response outcome \\
\hline Genotype dependent? & Yes & Yes & Yes \\
\hline
\end{tabular}

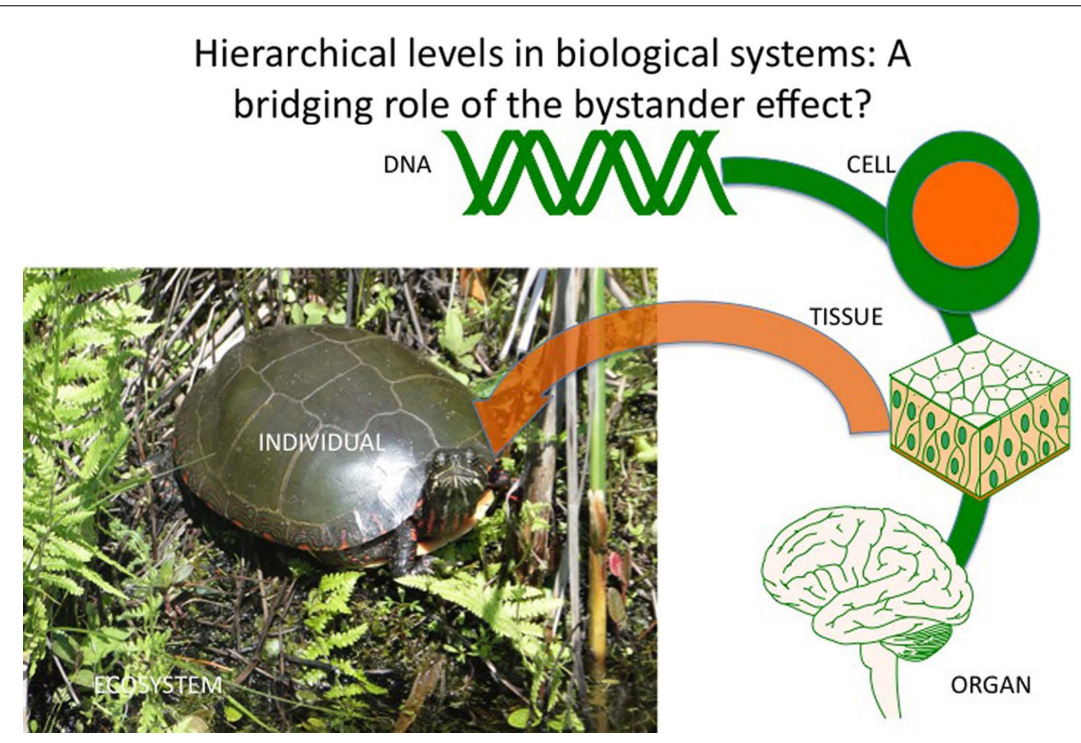

FIGURE 3 | Hierarchical levels in biological systems indicating a coordinating role for stress-induced bystander effects.

may lead to random and unpredictable consequences, which are intrinsically chaotic and can only be assessed (if at all) at levels of organization much greater than those at which the events occur (Figure 3). The argument against it being true is the reproducibility of effects, which would suggest that the response to random ionizations becomes coordinated suggesting an emergent property of the system similar to quorum sensing in bacteria.

\section{WIDER IMPLICATIONS OF NON-TARGETED EFFECTS IN GENETICS AND EPIGENETICS}

Bystander effects and genomic instability have revolutionized low dose radiobiology, leading to questions about radiation risk and carcinogenesis and suggesting new targets for cancer therapy (Mothersill and Seymour, 2006; Prise and O'Sullivan, 2009). Have they wider implications in biology? Certainly the mechanisms involved suggest a key role for electromagnetic radiation in cell signaling and that this signaling is key to coordinating responses at higher levels of organization - providing a communication system which is highly responsive to environmental conditions. The involvement of neural-like processes such as depolarization of membranes, involvement of neurotransmitter binding to ion-gated channel receptors and ion-fluxes across membranes (Lyng et al., 2000, 2006; Poon et al., 2007; Saroya et al., 2009) is exciting and may provide a mechanism for such 
alternative medicine therapies as Reiki and acupuncture, which employ the concept of a "biofield" in living organisms, coordinating health and well being. At the genetic level, the phenomena challenge gene-centric paradigms and suggest the existence of mechanisms even more epigenetic than those such as histone acetylation, mRNA's, or mitochondrial inheritance which are causing so much excitement at present (Calvanese et al., 2012). Non-targeted effects especially if mediated by an electromagnetic information transfer system may provide some very interesting science.

\section{REFERENCES}

Bréchignac, F., Bradshaw, C., Carroll, S., Jaworska, A., Kapustka, L., Monte, L., and Oughton, D. (2011). Recommendations from the International Union of Radioecology to improve guidance on radiation protection. Integr. Environ. Assess. Manag. 7, 411-413.

Calabrese, E. J., Stanek, E. J. III, and Nascarella, M. A. (2011). Evidence for hormesis in mutagenicity doseresponse relationships. Mutat. Res. 726, 91-97.

Calvanese, V., Lara, E., and Fraga, M. F. (2012). Epigenetic code and selfidentity. Adv. Exp. Med. Biol. 738, 236-255.

Hall, E. J., and Giaccia, A. J. (2006). Radiobiology for the Radiologist, 6th Edn. Philadelphia: Lippincott, Williams and Wilkins.

Hamada, N., Maeda, M., Otsuka, K., and Tomita, M. (2011). Signaling pathways underpinning the manifestations of ionizing radiation-induced bystander effects. Curr. Mol. Pharmacol. 4, 79-95.

Hei, T. K., Zhou, H., Ivanov, V. N., Hong, M., Lieberman, H. B., Brenner, D. J., Amundson, S. A., and Geard, C. R. (2008). Mechanism of radiationinduced bystander effects: a unifying model. J. Pharm. Pharmacol. 60, 943-950.

Ilnytskyy, Y., Koturbash, I., and Kovalchuk, O. (2009). Radiationinduced bystander effects in vivo are epigenetically regulated in a tissue-specific manner. Environ. Mol. Mutagen. 50, 105-113.

Kadhim, M. A., MacDonald, D. A., Goodhead, D. T., Lorimore, S. A., Marsden, S. J., and Wright, E. G. (1992). Transmission of chromosomal instability after plutonium alpha-particle irradiation. Nature 355, 738-740.

Kaup, S., Grandjean, V., Mukherjee, R., Kapoor, A., Keyes, E., Seymour, C. B., Mothersill, C. E., and Schofield, P. N. (2006). Radiation-induced genomic instability is associated with DNA methylation changes in cultured human keratinocytes. Mutat. Res. 597, 87-97.
Kovalchuk, O., Zemp, F. J., Filkowski, J. N., Altamirano, A. M., Dickey, J. S., Jenkins-Baker, G., Marino, S. A., Brenner, D. J., Bonner, W. M., and Sedelnikova, O. A. (2010). MicroRNAome changes in bystander threedimensional human tissue models suggest priming of apoptotic pathways. Carcinogenesis 31, 1882-1888.

Kuhn, T. S. (1970). The Structure of Scientific Revolutions, 2nd Edn, Foundations of the Unity of Science. Chicago: The University of Chicago Press.

Lamarck, J. B. (1963). Zoological Philosophy, an Exposition with Regard to the Natural History of Animals, trans. Hugh Elliot. New York: Hafner Publ. Co.

Loeb, L. A. (2011). Human cancers express mutator phenotypes: origin, consequences and targeting. Nat. Rev. Cancer 11, 450-457.

Lorimore, S. A., Coates, P. J., and Wright, E. G. (2003). Radiationinduced genomic instability and bystander effects: inter-related nontargeted effects of exposure to ionizing radiation. Oncogene 22, 7058-7069.

Lyng, F. M., Maguire, P., McClean, B., Seymour, C., and Mothersill, C. (2006). The involvement of calcium and MAP kinase signaling pathways in the production of radiationinduced bystander effects. Radiat. Res. 165, 400-409.

Lyng, F. M., Seymour, C. B., and Mothersill, C. (2000). Production of a signal by irradiated cells which leads to a response in unirradiated cells characteristic of initiation of apoptosis. Br. J. Cancer 83, 1223-1230.

Mendonca, M. S., Kurohara, W., Antoniono, R., and Redpath, J. L. (1989). Plating efficiency as a function of time postirradiation: evidence for the delayed expression of lethal mutations. Radiat. Res. 119, 387-393.

Morgan, W. F. (2003a). Non-targeted and delayed effects of exposure to ionizing radiation: I. Radiationinduced genomic instability and bystander effects in vitro. Radiat. Res. 159, 567-580.

\section{CONCLUSION}

This review discusses the key phenomena, which are challenging our understanding of radiation action in living systems. The controversies and implications are then considered. Finally the implications for biology in its widest sense are considered.

\section{ACKNOWLEDGMENTS}

The authors acknowledge financial support from the Canada Research Chairs Programme (Carmel Mothersill) and the NSERC Industrial Research Chairs Programme (CBS).

Morgan, W. F. (2003b). Non-targeted and delayed effects of exposure to ionizing radiation: II. Radiationinduced genomic instability and bystander effects in vivo, clastogenic factors and transgenerational effects. Radiat. Res. 159, 581-596.

Morgan, W. F. (2011). Communicating non-targeted effects of ionizing radiation to achieve adaptive homeostasis in tissues. Curr. Mol. Pharmacol. 4, 135-140.

Mothersill, C., Kadhim, M. A., O'Reilly, S., Papworth, D., Marsden, S. J., Seymour, C. B., and Wright, E. G. (2000). Dose- and timeresponse relationships for lethal mutations and chromosomal instability induced by ionizing radiation in an immortalized human keratinocyte cell line. Int. J. Radiat. Biol. 76, 799-806.

Mothersill, C., Lyng, F., Seymour, C., Maguire, P., Lorimore, S., and Wright, E. (2005). Genetic factors influencing bystander signaling in murine bladder epithelium after low-dose irradiation in vivo. Radiat. Res. 163, 391-399.

Mothersill, C., and Seymour, C. (1997). Medium from irradiated human epithelial cells but not human fibroblasts reduces the clonogenic survival of unirradiated cells. Int. J. Radiat. Biol. 71, 421-427.

Mothersill, C., and Seymour, C. (2001). Radiation-induced bystander effects: past history and future directions. Radiat. Res. 155, 759-767.

Mothersill, C., and Seymour, C. (2006). Radiation-induced bystander and other non-targeted effects: novel intervention points in cancer therapy? Curr. Cancer Drug Targets 6, 447-454.

Mothersill, C., and Seymour, C. (2012). Changing paradigms in radiobiology. Mutat. Res. [Epub ahead of print].

Mothersill, C., Smith, R. W., Fazzari, J., McNeill, F., Prestwich, W., and Seymour, C. B. (in press). Evidence for a physical component to the radiation-induced bystander effect. Int. J. Radiat. Biol.
Mothersill, C., Smith, R. W., Saroya, R., Denbeigh, J., Rowe, B., Banevicius, L., Timmins, R., Moccia, R., and Seymour, C. B. (2010). Irradiation of rainbow trout at early life stages results in legacy effects in adults. Int. J. Radiat. Biol. 86, 817-828.

Murphy, J. B., and Norton, J. J. (1915). The effect of $\mathrm{x}$-ray on the resistance to cancer in mice. Science 42, 842-843.

Nagasawa, H., and Little, J. B. (1992). Induction of sister chromatid exchanges by extremely low doses of alpha-particles. Cancer Res. 52, 6394-6396.

O'Reilly, S., Mothersill, C., and Seymour, C. B. (1994). Postirradiation expression of lethal mutations in an immortalized human keratinocyte cell line. Int. J. Radiat. Biol. 66, 77-83.

Poon, R. C., Agnihotri, N., Seymour, C., and Mothersill, C. (2007). Bystander effects of ionizing radiation can be modulated by signaling amines. Environ. Res. 105, 200-211.

Prise, K. M., and O'Sullivan, J. M. (2009). Radiation-induced bystander signalling in cancer therapy. Nat. Rev. Cancer 9, 351-360.

Saroya, R., Smith, R., Seymour, C. and Mothersill, C. (2009). Injection of reserpine into zebrafish, prevents fish to fish communication of radiation-induced bystander signals: confirmation in vivo of a role for serotonin in the mechanism. Dose Response 8, 317-330.

Seymour, C. B., and Mothersill, C. (1988). Clonogenicity of the progeny of surviving cells after irradiation. Int. J. Radiat. Biol. 54, 497-504. Seymour, C. B., and Mothersill, C. (1997). Delayed expression of lethal mutations and genomic instability in the progeny of human epithelial cells that survived in a bystanderkilling environment. Radiat. Oncol. Investig. 5, 106-110.

Seymour, C. B., Mothersill, C., and Alper, T. (1986). High yields of lethal mutations in somatic mammalian cells that survive ionizing radiation. Int. J. Radiat. Biol. Relat. Stud. Phys. Chem. Med. 50, 167-179. 
Sgouros, G., Knox, S. J., Joiner, M. C., Morgan, W. F., and Kassis, A. I. (2007). MIRD continuing education: bystander and low dose-rate effects: are these relevant to radionuclide therapy? J. Nucl. Med. 48, 1683-1691.

Surinov, B. P., Isaeva, V. G., and Tokarev, O. I. U. (2001). Allelopathic activity of volatile secretions in irradiated animals. Radiats. Biol. Radioecol. 41, 645-649.
Tamminga, J., and Kovalchuk, O. (2011). Role of DNA damage and epigenetic DNA methylation changes in radiation-induced genomic instability and bystander effects in germline in vivo. Curr. Mol. Pharmacol. 4, 115-125.

Vines, A. M., Lyng, F. M., McClean, B., Seymour, C., and Mothersill, C. E. (2008). Bystander signal production and response are independent processes which are cell line dependent. Int. J. Radiat. Biol. 84, 83-90.
Conflict of Interest Statement: The authors declare that the research was conducted in the absence of any commercial or financial relationships that could be construed as a potential conflict of interest.

Received: 19 March 2012; accepted: 20 April 2012; published online: 17 May 2012.

Citation: Mothersill $C$ and Seymour $C$ (2012) Are epigenetic mechanisms involved in radiation-induced bystander effects? Front. Gene. 3:74. doi: 10.3389/fgene.2012.00074

This article was submitted to Frontiers in Epigenomics, a specialty of Frontiers in Genetics.

Copyright (C) 2012 Mothersill and Seymour. This is an open-access article distributed under the terms of the Creative Commons Attribution Non Commercial License, which permits noncommercial use, distribution, and reproduction in other forums, provided the original authors and source are credited. 